\title{
As concepções de público no pensamento industrial cinematográfico*
}

\begin{abstract}
RESUMO
Este artigo examina as concepções de público desenvolvidas entre as décadas de 1920 e 1970 por diretores, produtores e críticos ligados ao cinema brasileiro. $\mathrm{Na}$ busca pela compreensão a respeito das possibilidades de industrialização da produção brasileira, esta foi uma das questões que mobilizaram a corporação cinematográfica, posto que entender o público foi visto como uma chave para se fazer filmes que alcançassem boas bilheterias. Da crença no patriotismo do brasileiro, passando pela perspectiva da necessidade de inculcar valores nacionais no povo, até a busca de se compreender quais as preferências culturais dos espectadores, temos um quadro variado de concepções sobre o público.
\end{abstract}

\section{PALAVRAS-CHAVE}

cinema brasileiro

indústria cinematográfica

história do cinema

\section{ABSTRACT}

This article examines several conceptions of publicas developed by directors, producers and critics related to the Brazilian cinema between the decades of 1920 and 1970. In the search for understanding the possibilities of the Brazilian production, this was one of the issues that mobilized the filmic context, since the public opinion was seen as a key to making films that achieve good ticket selling. From the belief in the Brazilian patriotism, passing through the prospect of the need to inculcate national values in the people, to the search to understand what are the cultural preferences of viewers, we have a framework of varied ideas about the public.

\section{KEY WORDS}

brazilian cinema

film Industry

film history

\section{Arthur Autran}

Professor do Departamento de Artes e Comunicação da UFSCar/SP/BR autran@powerufscarbr

\section{0 idealismo patriótico}

O público cinematográfico sempre foi tema relevante entre aqueles que buscaram entender as razões do sucesso ou do fracasso de um filme. Imaginar, projetar, compreender e analisar o público seriam formas de propiciar a produtores, cineastas, legisladores e críticos informações que possibilitassem saber por quais razões uma película conseguia atingir boa bilheteria ou não, bem como quais as influências que os filmes deveriam exercer sobre a platéia.

Tal não foi diferente em relação ao cinema brasileiro. O meu objetivo neste texto é apontar para algumas das principais formas pelas quais o público do cinema nacional foi pensado desde os anos 1920 até a década de 1970 por produtores, críticos e diretores.

No caso brasileiro, assim como de diversas outras cinematografias cujas formas de produção não lograram se desenvolver economicamente em bases sólidas, é necessário ter em vista que a discussão a respeito do público tem como marco ideológico o princípio propalado por exibidores e distribuidores estrangeiros de que os espectadores prefeririam o filme norte-americano ao nacional.

Ainda na década de 1920 temos na campanha do cinema brasileiro levada a cabo pelos jornalistas cariocas Adhemar Gonzaga e Pedro Lima nas revistas Para Todos, Selecta e Cinearte a preocupação com a questão do público. No que pese a posição errática dos dois jornalistas, eles tendem a não concordar com os exibidores, os quais já na época afirmavam que o domínio do filme norte-americano se devia à preferência do público por um produto com melhor qualidade. Pedro Lima, por exemplo, assevera que apenas o público tem "boa vontade" com o cinema brasileiro (Lima, 1924), enquanto Adhemar Gonzaga entende que por meio da "exigência do público" seria possível vencer a "má vontade" de exibidores e distribuidores em relação ao filme nacional (Gonzaga, 1926). Além disso, a campanha lança o slogan "Todo filme brasileiro deve ser visto", sempre estampado nas colunas de Adhemar Gonzaga e Pedro Lima em Cinearte, e que aponta para a crença cristalina no apelo ao patriotismo do público. Esta confiança atravessou diferentes momentos e grupos da produção cinematográfica ao longo da história.

Note-se que a perspectiva da ação do público como antes de tudo necessariamente patriótica acaba por elidir os seus diferentes tipos - de elite, classe média, popular etc. - e já aponta de alguma forma para a confusão do público com povo, um correspondendo ao outro. 


\section{Público $=$ Povo}

Foi o grupo de cineastas ligados ao Cinema Independente, já nos anos 1950, que efetivamente desenvolveu o pensamento em torno da questão da importância do mercado interno para a consolidação da indústria por meio da imbricação com a idéia de público. Formado por nomes como Nelson Pereira dos Santos, Rodolfo Nanni, Alex Viany, Roberto Santos e Carlos Ortiz, o grupo do Cinema Independente entendia que a indústria era inviável sem embasamento econômico efetivo representado por fomento financeiro regular, distribuição adequada e predomínio no mercado interno.

Tanto Nelson Pereira dos Santos quanto Rodolfo Nanni enfatizaram nas suas teses apresentadas ao I Congresso Paulista do Cinema Brasileiro - ocorrido em 1952 - a importância dos temas nacionais, aquele inclusive sustentando que o conteúdo teria primazia sobre a técnica em termos de relevância junto ao público ${ }^{1}$. Segundo Nanni, o ponto fundamental para se chegar à industrialização era expressar "a vida, os costumes e a história" do povo, mas não se justifica tal asserção. Nelson Pereira dos Santos articula melhor sua posição ao explicar que os temas nacionais - provenientes da literatura, do folclore ou de eventos históricos - são "fator decisivo para o progresso material do cinema brasileiro" já que "o nosso público aprecia em primeiro lugar as histórias dos filmes brasileiros" pois deseja ver "o reflexo de sua vida, de seus costumes, de seus tipos", decorrendo daí que se a produção nacional optar pela temática brasileira o público corresponderá nas bilheterias; outrossim, como o analfabetismo era muito alto a questão da língua colocava o cinema brasileiro em vantagem frente à produção de outros países em termos de preferência dos espectadores.

Chama atenção o arcabouço ideológico com que a noção de público surge nos congressos de cinema realizados entre 1952 e $1953^{2}$. Muitas vezes, tal como na tese de Nelson Pereira dos Santos, público e povo são termos equivalentes utilizados de forma praticamente indistinta, levando à idéia de que se o público apóia o cinema nacional logo o povo também e justificando plenamente o auxílio governamental. Observe-se que a concepção de público exposta por um dos mais importantes produtores da época, Mario Civelli - figura desligada do grupo do Cinema Independente -, possuía pontos de contato com a idéia expressa por Nelson Pereira dos Santos. Para Civelli:

O público perdoa uma fotografia mais ou menos. $\mathrm{O}$ público não liga muito para a qualidade de som, isto é, não se importa se o som é feito com aparelhos de fama internacional, se a modulação dos baixos e agudos é perfeita. O público quer discernir o que os atores dizem e o que a orquestra toca. O que o público quer é uma história boa. Uma história que diga algo para todo mundo, seja esse banqueiro ou camponês (Civelli, 1952).

Civelli não dá importância para a questão da temática brasileira, mas insiste na preponderância da história para conquistar o público em detrimento da técnica ou da estética, além de repisar a idéia do público indistinto, sem estratificações, embora não se relacione diretamente o público com o povo.

A concepção de que público e povo se confundem, expressa de forma admirável por Nelson Pereira dos Santos, traz no seu bojo o entendimento de que a defesa dos interesses do público, que preferiria o cinema nacional, representaria defender o próprio interesse popular. Assim, apoiando e protegendo a produção cinematográfica nacional o governo estimularia a produção de filmes que refletissem a "verdadeira" cultura nacional e impediria a conspurcação desta pelo filme estrangeiro.

\section{Público $=$ Consumidor}

Em 1955 dois membros da Comissão Municipal de Cinema paulistana, Francisco Luiz de Almeida Salles e Jacques Deheinzelin, prepararam extenso relatório que serviria de subsídio à Secretaria de Educação e Cultura para esta enviar um projeto de lei à Câmara Municipal visando apoiar o cinema nacional (Salles; Deheinzelin, 1955). O documento tem a sombra da derrocada fragorosa da Cia. Cinematográfica Vera Cruz no ano anterior e foi elaborado de forma a rebater de modo articulado a argumentação dos exibidores a respeito da preferência do público pelo filme estrangeiro. Calculando as rendas médias dos filmes estrangeiros e as dos brasileiros, o relatório concluía que as dos primeiros eram bem inferiores as dos produzidos pela Vera Cruz, Maristela e Multifilmes, atestando a preferência do público pelo filme brasileiro.

O relatório é contemporâneo da longa e confusa discussão sobre o tabelamento de preços dos ingressos, considerado no documento "o principal fator da crise que a indústria cinematográfica nacional está atravessando". Anita Simis registra que o tabelamento entrou em vigor em 1948 e os preços variavam de acordo com a categoria das salas de exibição. Ao longo dos anos houve alterações na quantidade de categorias, mas o elemento básico para definir aquela de preço mais elevado era o fato de o cinema ser "lançador", ou seja, o primeiro na cidade a exibir determinada fita (Simis, 1996, pp. 185188). Esta intervenção no mercado gerou viva polêmica em meados do decênio de 1950, pois foi percebida por alguns setores da corporação como um dos principais entraves para o florescimento da produção cinematográfica nos moldes empresariais empregados pela Vera Cruz e para a viabilização econômica de realizações com maior "qualidade" técnica e artística.

Em 1955, visando dar uma solução para o problema, 
longo documento assinado pelos principais críticos dos jornais paulistanos é dirigido a Ubirajara Zogaib, então diretor do Departamento de Estudos e Planejamento da COAP (Comissão de Abastecimento e Preços) - órgão responsável pelo tabelamento -, no qual a partir da consideração que "o equívoco da política de preços a que está submetido o cinema nacional consiste em encarar o público dentro de uma homogeneidade e não de uma heterogeneidade de capacidade de consumo", solicita-se a liberação dos preços nos cinemas tão-somente quando da exibição de filmes brasileiros. Com tal medida esperava-se: a tendência do exibidor em programar mais filmes brasileiros e por maior tempo, pois estes seriam mais lucrativos quando comparados aos estrangeiros; estabelecer um "regime de rendas" atendendo às necessidades do "desenvolvimento industrial" do cinema brasileiro, invertendo a situação então em vigor que beneficiava apenas a concorrência estrangeira; aumentar a "qualidade" do nosso produto 3 .

O fundamento da proposta dos críticos à COAP está baseado na variedade sócio-econômica do público, que ressurge de forma bastante diferente quando comparado ao bloco homogêneo da esquerda nacionalista ou mesmo o idealizado pelo produtor Mario Civelli. Flávio Tambellini, possivelmente o mais engajado nesta campanha pelo aumento de preços, considerava que:

Toda a inteligência comercial de uma política de preços está em surpreender camadas consumidoras diferentes com diferentes preços, oferecendo a $\mathrm{Cr} \$ 8,00$ a entrada para aquela camada para a qual Cr\$ 10,00 é caro, mas oferecendo também a $\mathrm{Cr} \$$ 20,00 àquela outra camada que dá $\mathrm{Cr} \$ 5,00$ ao vagalume para lhe encontrar um lugar, que compra $\mathrm{Cr} \$$ 50,00 de bombom e que gratifica com $\operatorname{Cr} \$ 10,00$ a quem fingiu que lhe tomou conta do seu carro. Dizer que não há um público imenso de cinema que pode e não se importa em absoluto de pagar a mais, porque o seu problema se mede a partir dos mil cruzeiros e não a partir de um cruzeiro é cometer um absurdo (Tambellini, 1955).

A expectativa do articulista para com o aumento de preços era tão grande que ele chega a prever "grande corrida dos exibidores para o cinema nacional", pela possibilidade de aumento do lucro. Também os produtores teriam a possibilidade de buscar outros assuntos e de um novo "padrão de realização".

Aparentemente é neste momento que surge a concepção de público como consumidor e a apreensão da estratificação deste em vários tipos de acordo com o poder aquisitivo. Também chama atenção na proposta a tentativa de associar o exibidor ao produtor nacional através do apelo econômico, rompendo a ligação existente entre aquele e o distribuidor de filmes estrangeiros, e não mais por meio do apelo ao patriotismo do exibidor ou apenas pela coerção legal via lei de cota de tela.

Entretanto, a proposta de elevação dos preços dos ingressos somente para os filmes brasileiros tem problemas tão evidentes que foram notados na época mesmo da sua proposição por figuras historicamente pouco expressivas, como o crítico cinematográfico comunista Francisco Amazonense.

O raciocínio, contrário ao exposto pelo Sr. Tambellini, nos parece muito simples para qualquer pessoa com um mínimo de lucidez e de clareza, diante desta realidade incontestável de um país semi-colonial e semi-feudal: pode o filme brasileiro encontrar-se em posição de vantagem, diante do filme estrangeiro (norte-americano, principalmente), quando é cobrado do público um preço mais elevado, o dobro, exatamente, do que o filme estrangeiro? Deve saber o Sr. Tambellini de um fato incontestável: o público não dá preferência ao produto nacional pelo simples fato de ser nacional, posto em concorrência com o produto estrangeiro, mas, exatamente, se ele, o produto nacional, oferece melhores condições de preço (Amazonense, 1955).

O crítico argumenta ainda que o público dos cinemas é formado majoritariamente pelas classes média e operária, já a burguesia possuiria condições econômicas de freqüentar outras formas de diversão que a afastariam do cinema. Note-se também que o próprio relatório elaborado por Almeida Salles e Jacques Deheinzelin recomendava o aumento de preços dos ingressos, mas de forma generalizada, sem incidir apenas sobre o produto nacional. Outro problema que poderia ser apontado na sugestão do aumento de preço do ingresso para o filme nacional, mas não o foi por Francisco Amazonense, é que o público deste em geral era o mais pobre, que até por não conseguir ler as legendas optava por ele.

Toda esta discussão demonstra a dificuldade de avançar na compreensão da economia cinematográfica brasileira ou em direção às possíveis soluções que levassem à industrialização da produção. Se por um lado a proposta encabeçada por Flávio Tambellini possibilitou a reflexão mais afinada sobre o público cinematográfico e buscou mesmo uma forma de associação econômica entre produtores e exibidores, por outro lado pecava pela renitente insistência na "qualidade" e na falta de observação para com a estrutura do mercado efetivamente existente.

\section{Em busca do público consciente e do público popular}

Segundo Jean-Claude Bernardet uma característica fundamental do Cinema Novo era que o autor se opunha ao espectador do ponto de vista das idéias; a relação proposta era, portanto, de conflito. Se isto, por um lado, teve efeitos positivos artisticamente, por outro, acarretou problemas econômicos já que o público se afastava dos 
filmes (Bernardet, 1978, pp. 197-204). Esta relação, notese, era bastante diferente da defendida pelos cineastas ligados ao Cinema Independente, incluindo Nelson Pereira dos Santos e Alex Viany, que trabalhavam na perspectiva de identificação com o público-povo, alcançada através do "reflexo" da vida deste na tela.

Tal oposição não era inconsciente e nem ingênua, bastando atentar para a seguinte afirmação de David Neves: "O cinema brasileiro sempre lutou contra a dose de má vontade de um público mal informado e comodista que não enfrenta a fita a que assiste e se comporta de forma passiva, receptora" (Neves, 1966, p. 17).

Apesar do elitismo que perpassa a citação acima, o projeto visando despertar o espectador da passividade enquadra-se plenamente na modernidade artística e tem sua eficácia criativa comprovada pela permanência estética de vários filmes do Cinema Novo. Porém, ao mesmo tempo, o Cinema Novo pretendia buscar ampliar o seu espaço no mercado, lançando o movimento numa encruzilhada que é percebida por Gustavo Dahl.

\section{Menino de engenho, São Paulo S. A., Matraga e A gran- de cidade procuram voluntariamente aproximar-se do público. De fato, venceram essa lentidão exaspe- rante considerada como uma das características do cinema brasileiro e passaram a colocar na tela sen- timentos um pouco menos abstratos, obscuros e radicais do que os filmes da primeira fase [do Cine- ma Novo]. O público correspondeu e, com algumas diferenças, esses filmes obtiveram maior êxito co- mercial do que os precedentes. Mas ocorreu tam- bém um enfraquecimento, uma diluição da subs- tância ideológica que representava o mérito principal de filmes como Barravento e Cinco vezes favela (Dahl, 1966/1967).}

O Cinema Novo ao buscar ampliar seu público para além da classe média intelectualizada no final dos anos de 1960, o fez a partir de necessidades econômicas decorrentes da falta de acesso mais amplo aos recursos do Estado, à interrupção dos investimentos provenientes da burguesia nacionalista e ao fim das ilusões em relação ao mercado externo. Isto evidentemente acarretou mudanças artísticas nos filmes de forma a torná-los atraentes para um círculo maior de espectadores. Os realizadores viam-se, a partir de então, constrangidos a optar entre buscar a consolidação econômica da atividade ou aprofundar as investigações estéticas e ideológicas ou ainda formular uma solução que conseguisse conciliar os dois eixos. Das respostas daí advindas é que se colocam as questões para boa parte da produção cinematográfica brasileira dos anos de 1970 e 1980.

Respostas como a enunciada por Todas as mulheres do mundo (Domingos de Oliveira, 1967), película que alcançou notável sucesso de bilheteria, geravam reações das mais virulentas do ponto de vista político. Jean-Claude
Bernardet considerou Todas as mulheres do mundo uma negação do Cinema Novo, pois incorreria no "irracionalismo" ao afirmar as relações humanas com o mundo como casuais.

E é com um cinema irracional, a-problemático (não há problemas no acaso), que o Brasil poderá erguer uma indústria e um comércio cinematográfico; Domingos de Oliveira aponta, com segurança e talento, o caminho. Pois é exatamente este o cinema que quer a classe média. $O$ festival de cinema brasileiro de Brasília, ao dar o primeiro prêmio a Todas as mulheres do mundo, sancionou (e o Itamarati confirmou ao escolher a fita para Cannes) o interesse que o público, certa intelectualidade e as autoridades têm em que se faça no Brasil um cinema risonho e irracional (Bernardet, 1978, p. 203-204).

Para o ensaísta, havia uma contradição presente no projeto industrialista que a seu ver tomara forma no interior do Cinema Novo: ao evitar o confronto com o público renunciava-se à ideologia nacional-popular esquerdista e aceitava-se tacitamente a ideologia dominante, esposada e defendida pelo público de classe média.

Gustavo Dahl também se deteve sobre a relação entre o Cinema Novo e o público muito especialmente no texto citado acima, no qual, vimos, assume a "diluição da substância ideológica" nos filmes mais recentes do movimento. No entanto, ele problematiza de outra forma a questão, reconhecendo que o público das fitas era composto basicamente por estudantes, profissionais liberais, artistas, intelectuais, setores da burguesia e cinéfilos, pondera que mesmo este conjunto de espectadores não estava satisfeito com os filmes.

Os intelectuais brasileiros preocupam-se cada vez mais com a comunicação de massa e, na medida em que reconhecem ao Cinema Novo o título de movimento cultural importante, lamentam aquilo que se denomina de seu hermetismo ou, para dar um tom político, seu divórcio das massas. (...). A dedicação das elites intelectuais, e mesmo de determinados integrantes da burguesia nacional, pela causa popular, deixa-nos entrever um futuro brilhante para a evolução social do Brasil, porém não resolve a questão que atormenta todo o Cinema Novo: como vencer a contradição entre um cinema responsável no nível do pensamento e da linguagem e sua aceitação pelo público (Dahl, 1966/1967).

Para o autor, a "contradição" estaria inscrita no próprio momento que a cinematografia mundial atravessava, marcado pela ascensão do "cinema moderno". Este processo representou "liberdade" para o "autor", cujo "auge" teria sido alcançado em Acossado (A bout de souffle, Jean-Luc Godard, 1959), mas a custa da perda do 
público. Daí porque apesar de se desejar intensamente que o Cinema Novo fosse "participante e ao alcance do povo", ele seguia a tendência geral de ter como platéia basicamente a juventude.

Tal como os índios que vêem as grandes cidades e depois morrem de melancolia, sem poder aceitar de novo os valores de sua sociedade, que sabem desde então condenada, os cineastas brasileiros entreviram a possibilidade de uma civilização que não se apresente como vítima de si própria, à maneira do mundo subdesenvolvido, que portanto se recusam a aceitar. Esta visão coloca-os à frente da sociedade brasileira em geral, da mesma forma que a região industrial do Rio e de São Paulo se encontra em relação ao resto do Brasil (Dahl, 1966/1967).

Pelo trecho acima podemos depreender que não se trata de o cineasta confrontar o público, como queriam Jean-Claude Bernardet e David Neves, mas que a sua posição social estaria à frente dos demais setores, cabendo-lhe uma espécie de postura iluminista esclarecendo aos outros qual o caminho a seguir. O confronto poderia até surgir, mas não era a única via possível. Chama a minha atenção a comparação positiva dos cineastas com as regiões industrializadas do país, no sentido de ambos estarem na dianteira do processo social nacional, pois fica evidente o que se poderia chamar de desejo industrial, ou seja, a vontade de o cinema também alcançar o grau de desenvolvimento produtivo de outras atividades econômicas instaladas nas cidades mencionadas. Porém, ao mesmo tempo a comparação se relaciona com os índios, vistos no texto como representantes de uma cultura em processo de extinção. Simples metáfora nacionalista ou reconhecimento das dificuldades de mudança na produção cinematográfica e na própria sociedade brasileira? O que surge involuntariamente é a imagem de um índio - o cineasta brasileiro atado às concepções do nacional-popular? - deslocado por não conseguir apreender a grande cidade repleta de indústrias.

Através da exposição das posições de Jean-Claude Bernardet e Gustavo Dahl fica bem claro o dilema enfrentado pelo Cinema Novo, de ao mesmo tempo desejar o aprofundamento das propostas estéticas e ideológicas dos filmes, mas também de atingir um público maior, e isto tanto para a afirmação econômica do movimento como visando à ampliação de sua influência na sociedade brasileira.

O filme que significou um verdadeiro marco divisório no contexto do Cinema Novo servindo para a definição de posições foi certamente Garota de Ipanema (Leon Hirszman, 1967).

Ao comentar El Justicero (Nelson Pereira dos Santos, 1966) e Garota de Ipanema, mas enfocando principalmente o segundo, Jean-Claude Bernardet informa que pela "primeira vez" o problema da conquista do público era enfrentado pelos "intelectuais", registrando a importância do fato. Na perspectiva de Bernardet, para se alcançar tal objetivo dever-se-ia oferecer ao público o que ele desejava, pois existiria "incompatibilidade entre o público e um cinema realmente crítico cuja perspectiva, na América Latina, será forçosamente política", tratar-se-ia, pois, de uma oposição insolúvel. Restaria ao cineasta optar pelo cinema "realmente crítico" ou por aquele que permitiria a consolidação industrial; no primeiro caso abandonando as preocupações econômicas, no segundo, as políticas. Qualquer solução que buscasse encaminhar as duas questões era repelida, pois: "O coquetel Glauber Rocha - Mazzaropi não tem futuro". O autor entendia que filmes com "público relativamente restrito", porém polêmicos em termos do tratamento dos problemas do Brasil poderiam cumprir importante papel, indicando para a concepção de uma espécie de público de vanguarda - política e estética (Bernardet, 1978, pp. 204-207).

O crítico não atina para o problema da total falta de retorno financeiro dos filmes politicamente engajados da primeira fase do Cinema Novo, fator determinante nas novas posições dos cineastas ligados ao movimento. É interessante notar aí como uma crítica de corte marxista, a princípio materialista, pode se tornar idealista ao desprezar a constrição econômica concreta que motivou os cinemanovistas. Ademais, a descrença de que apelo junto ao público e criticidade pudessem estar imbricados numa mesma obra surge tão-somente como um desejo do crítico projetado sobre a realidade, pois ao longo da história do cinema não são poucos os casos de obras críticas que alcançaram sucesso comercial.

Bem diferente foi a posição exposta por Gustavo Dahl. Antes mesmo de Garota de Ipanema ficar pronto, ele entende que o filme anunciaria "uma nova atitude em relação ao público, tentando comunicar-se com ele através dos mitos que ele mesmo cria", postura esta a seu ver incorporada pela nova safra de fitas do Cinema Novo. No afã de sublinhar a importância de Garota de Ipanema, chega-se de maneira bastante discutível a aproximá-lo de Terra em transe (Glauber Rocha, 1967), pois o primeiro filme estaria "no pólo oposto, mas do mesmo lado" em relação ao segundo, este considerado o "mais radical" do cinema brasileiro tanto esteticamente quanto ao nível da comunicação. Para Dahl, a razão que teria levado Leon Hirszman e outros diretores a buscar novas formas de contato com o público devia-se ao fato de que nos primeiros filmes do Cinema Novo o espectador não queria se reconhecer, sentindo-se "violentado" com o subdesenvolvimento exposto nas imagens e abandonando a sala de exibição (Dahl, 1967).

Fica implícito no conjunto da argumentação de Gustavo Dahl que o problema estava no espectador e não nos filmes, mas para possibilitar a conscientização do público era necessário antes de tudo que o filme o atraís- 
se, daí teoricamente a excelência da fórmula cinematográfica que trabalhava com a idéia de seduzi-lo com determinado elemento para em seguida formular a crítica a partir deste mesmo elemento, levando à exposição dos problemas sociais.

Dez anos depois da publicação deste texto os cineastas ligados ao Cinema Novo dominavam a Embrafilme ${ }^{4}$, inclusive com o próprio Gustavo Dahl dirigindo o setor de distribuição da empresa. Demonstrando coerência interna na teoria e na prática, ele publica em 1977 o conhecido ensaio "Mercado é cultura". Afirmando que a maior ambição de um país é produzir cinema na sua língua, o autor defende que:

O espectador quer ver-se na tela de seus cinemas, reencontrar-se, decifrar-se. A imagem que surge é a imagem do mito de Narciso, que, vendo seu reflexo nas águas, descobre sua identidade. A ligação entre uma tela de cinema - na qual é projetada uma luz, que se reflete sobre o rosto do espectador - à idéia de espelho, espelho das águas, espelho de uma nacionalidade, é uma idéia que está implícita num conceito de cinema nacional (Dahl, 1977).

Destaca-se a idéia do cinema como fator de identidade nacional, recorrente na história do cinema brasileiro, agora trabalhada de forma mais sofisticada, marcada por laivos de psicologia coletiva. Como sempre é o cinema a determinar a tal identidade, aceita pelo espectador de forma passiva. Na continuidade do raciocínio, afirma-se que o cinema precisa de acesso ao mercado, pois é aí que efetivamente a linguagem se realiza. Segundo Gustavo Dahl, “...e é válido dizer que 'mercado é cultura', ou seja, que o mercado cinematográfico brasileiro é, objetivamente, a forma mais simples da cultura cinematográfica brasileira" (Dahl, 1977).

A política da Embrafilme, para o articulista, teria a excelência de conjugar as expressões industrial e cultural, resultando objetivamente em situações como a de uma projeção de Xica da Silva (Carlos Diegues, 1976) na Zona Norte carioca, presenciada pelo próprio realizador, onde ocorreria uma "cerimônia antropológica" na qual "lazer" e "informação cultural" encontravam-se.

O público que surge do texto de Dahl é, portanto, o segmento popular das grandes cidades, e pela própria omissão da classe média fica indicado que esta passava a ocupar dimensão menor em relação à problemática da conquista do mercado quando comparado aos textos dos anos 1960.

A centralidade do público popular já encontrara sua defesa poucos anos antes numa manifestação de Nelson Pereira dos Santos. Para este diretor existiria uma multiplicidade de tipos de público, mas ele optara naquele momento em realizar O amuleto de Ogum (1974) pelo fato de a cultura do povo ser "oprimida e reprimida". Ainda segundo Nelson Pereira dos Santos caberia ao artista abandonar a postura intelectualista e não incorrer na opressão à cultura popular, mas sim buscar vivenciar o aspecto dela que se quer abordar, naquele caso específico a umbanda.

Eu acho que é uma perda de tempo ficar discutindo o que venha a ser cultura brasileira. Devemos pensar fundamentalmente nesse problema de mercado. O agente cultural brasileiro, seja ele escritor, cineasta, músico, ator ou qualquer pessoa de criação tem um mercado restrito porque até hoje compete com o produto importado, disputando o mesmo consumidor. E não vêem a grande massa que espera por eles (Santos, 1975).

Desaparece, pois, a necessidade de definição da cultura nacional anteriormente defendida com vigor pelo próprio Nelson Pereira dos Santos. A partir de então é somente no mercado que se daria a luta com o filme estrangeiro tanto economicamente quanto culturalmente. Ao optar pela centralidade do mercado, o cineasta já estaria pelo menos parcialmente se voltando para o grande público popular. Está exposta aí em germe a idéia de que "mercado é cultura", posteriormente elaborada por Gustavo Dahl.

Outra importante característica atribuída neste período ao público pelos egressos do Cinema Novo diz respeito à razão que levaria o popular a gostar do filme brasileiro e o de classe média a rejeitá-lo. Segundo Leon Hirszman, a atitude do primeiro justificar-se-ia pelo fato de que desde pequeno ele já estaria "envenenado" de Brasil, pelas doenças, pela imersão no contexto cultural, por ser espoliado; enquanto o espectador com "formação burguesa" teria resistência em relação à nossa produção. Aqui está em pleno processo de reconstrução ideológica o fato já então há muito divulgado, mas pouquíssimo estudado na época ou mesmo atualmente, dos setores populares preferirem determinados filões da produção brasileira à estrangeira. Se fizermos uma análise menos marcada pelo romantismo populista de esquer$\mathrm{da}$, talvez surjam outras razões como o analfabetismo em largas faixas da população, as ligações com outros tipos de espetáculo popular - rádio, televisão, circo e teatro de revista -, relações culturais profundamente arraigadas - o que não significa congeladas nem infensas ao que os intelectuais nacionalistas poderiam considerar a cultura estrangeira - etc.

Como o cineasta intelectual deve continuar mantendo a ilusão da sua importância com relação ao povo, até para que justifique para si e a sociedade os pleitos relacionados com a Embrafilme, ao fim e ao cabo não se pode aceitar pura e simplesmente a luta pelo mercado, pois aí as pornochanchadas teriam direito ao apoio do financiamento estatal. Por isso, Leon Hirszman observa: "O problema é que a repressão obriga o cinema brasileiro a utilizar os canais da alienação, dos recalques, as rela- 
ções de frustração existentes no seio da massa". Ou seja, não se tratava de defender qualquer filme brasileiro no mercado, mas especialmente aqueles que abordassem "os grandes temas de interesse nacional e de interesse popular" (Hirszman, 1975, p. 26).

Aqui o mercado não é mais o único definidor da expressão cultural, demonstrando que a discussão sobre as relações entre mercado e cultura tende a rodar em falso quando enunciada pelos egressos do Cinema Novo.

\section{Conclusão}

Este texto é parte de uma pesquisa de maior vulto na qual analisei as principais idéias desenvolvidas entre 1924 e 1990 pela corporação cinematográfica brasileira a respeito das formas de industrialização da produção de filmes. No recorte aqui exposto, em torno das concepções de público, há uma característica recorrente que eu gostaria de salientar.Tal característica tem fortes ressonâncias históricas e diz respeito ao fato de a idéia de público no período analisado não se constituir como uma abstração construída através de quaisquer tipos de estudos ou mesmo pesquisas empíricas, mas via de regra se trata de um constructo ideológico que serve para reafirmar as posições do cineasta ou do crítico no campo cultural afAMECOS

\section{NOTAS}

* Trabalho apresentado ao Grupo de Trabalho "Fotografia, Cinema e Vídeo", do XVII Encontro da Compós, na UNIP, São Paulo, SP, em junho de 2008.

1. A tese de Nelson Pereira dos Santos intitula-se "O problema do conteúdo no cinema brasileiro", a de Rodolfo Nanni, "O produtor independente e a defesa do cinema nacional". Agradeço a José Inácio de Melo Souza que cedeu ambos os documentos.

2. Além do já mencionado I Congresso Paulista do Cinema Brasileiro, ocorreu ainda em 1952 o I Congresso Nacional do Cinema Brasileiro e no ano seguinte o II Congresso Nacional do Cinema Brasileiro.

3. O documento foi assinado pelos seguintes críticos: Fernando de Barros, Francisco Luz de Almeida Salles, Luiz Carlos [Bresser] Pereira, Paulo Emílio Salles Gomes, Walter Rocha e Flávio Tambellini. Ele foi reproduzido em diversos jornais, tais como o Diário da Noite paulistano nos dias 10 e 11 de agosto de 1955.

4. A Embrafilme foi uma empresa criada pelo governo federal em 1969 ligada ao Ministério da Educação e Cultura. O papel da Embrafilme foi fundamental no avanço ocorrido na década de 1970 do cinema brasileiro no mercado interno, mas as polêmicas e disputas de ordem variada que sempre cercaram suas ati- vidades acabaram por minar sua credibilidade. A empresa foi extinta em 1990 pelo presidente Fernando Collor de Mello.

\section{REFERÊNCIAS}

AMAZONENSE, Francisco. Retorno à velha questão. In: Notícias de Hoje, São Paulo, 2 jun. 1955.

BERNARDET, Jean-Claude. Trajetória crítica. São Paulo: Polis, 1978.

CIVELLI, Mario. Experiências pessoais sobre o cinema nacional. In: A Cena Muda, Rio de Janeiro, n. 21, 22 maio 1952.

DAHL, Gustavo. Cinema Novo e seu público. In: Revista Civilização Brasileira, Rio de Janeiro, v. I, n. 11-12, dez. 1966 / mar. 1967.

DAHL, Gustavo. Cinema Novo em dois planos - Comunicação. In: Guanabara em Revista, Rio de Janeiro, n. 10, set. 1967.

DAHL, Gustavo. Mercado é cultura. In: Cultura, Brasília, v. VI, n. 24, jan. mar. 1977.

GONZAGA, Adhemar. Filmagem brasileira. In: Para Todos, Rio de Janeiro, v. VIII, n. 371, 23 jan. 1926.

HIRSZMAN, Leon; AVELLAR, José Carlos; VIANY, Alex. Cinema. In: Ciclo de debates no Teatro Casa Grande, Rio de Janeiro: Inúbia, 1976. pp. 12-38.

LIMA, Pedro. O cinema no Brasil. In: Selecta, Rio de Janeiro, v. X, n. 34, 23 ago. 1924.

NEVES, David. Cinema Novo no Brasil. Petrópolis: Vozes, 1966.

SALLES, Francisco Luiz de Almeida; DEHEINZELIN, Jacques. Indústria cinematográfica brasileira. In: Anhembi, São Paulo, v. XXI, n. 61, dez. 1955.

SANTOS, Nelson Pereira dos. Manifesto por um cinema popular. Depoimento a Marcelo Beraba. Rio de Janeiro: Federação dos Cineclubes do Rio de Janeiro / Cineclube Macunaíma / Cineclube Glauber, 1975.

SIMIS, Anita. Estado e cinema no Brasil. São Paulo: Annablume / Fapesp, 1996.

TAMBELLINI, Flávio. Cinema nacional e preço. In: Diário da Noite, São Paulo, 27 maio 1955. 